\title{
Wellbeing in Bhutan
}

\author{
Robert Biswas-Diener · Ed Diener · Nadezhda Lyubchik
}

\begin{abstract}
Gross National Happiness (GNH) is often recommended as a new approach to assessing economic and social development, and the small nation of Bhutan has become known for advocating this measure of quality of life. Little has been published on actual wellbeing outcomes of GNH policy in Bhutan. The current study uses a demographically representative sample to evaluate a variety of measures of quality of life in Bhutan. We compared 11 nations with Bhutan on 4 domains - Psychological, Social, Environmental, and Income and Material wellbeing. We found mixed results concerning Bhutan's wellbeing. Results from the study indicated that Bhutan ranks first in terms of Environmental wellbeing and ranks moderately high on Social wellbeing. However, it scores fairly low in terms of overall Psychological wellbeing. Thus, like many societies in the world, Bhutan is succeeding in some areas but remains challenged in other domains. Limitations and implications of the study are discussed.
\end{abstract}

Keywords: well-being, wellbeing, happiness, Bhutan, gross national happiness, public policy

\section{Introduction}

Wellbeing in general, and happiness specifically, has become a topic of policy interest in recent years (e.g. Diener, Lucas, Schimmack \& Helliwell, 2009; Diener, Oishi \& Lucas, 2015). Several lines of research have converged to allow for the focus on wellbeing. First, researchers have created psychometrically sound measures of wellbeing such as the Satisfaction with Life Scale (Diener et al., 2010; Pavot \& Diener, 1993). These measures have increasingly been scrutinized for their potential psychometric virtues and limitations and have been found to have reasonably strong reliability and validity (see Diener et al, 2010; Pavot \& Diener, 2008) and to converge with non-self-report measures (Sandvik, Diener, \& Seidlitz, 1993). As such, these instruments are useful in detecting differences in life satisfaction between groups of people, for measuring the relationship of wellbeing with other concepts such as health, and for predicting future behaviors (Diener, Inglehart, \& Tay, 2013). Second, advances in technology and research design have yielded insights into the nature of wellbeing (Clark, Diener, Georgellis, \& Lucas, 2008). As a result, researchers have increasingly called for wellbeing and similar subjective measures to be used alongside traditional economic and social indicators to guide policy (Diener et al., 2009), and statistical agencies have done so as well (OECD, 2013).

Among the factors most centrally implicated in the increasing popularity of wellbeing policy is the recent trend in research results pointing to the benefits of happiness. Some of the advantages of higher wellbeing include work and economic benefits such as higher prosperity, enjoyment, and increased productivity at work (Diener \& Tay, 2013) and higher incomes (DeNeve, Diener, Tay, \& Xuereb, 2013). There are also health benefits of happiness such as increased longevity (DeNeve, Diener, Tay, \& Xuereb, 2013) and lower psychological stress (Hooker \& Pressman, 2015). In addition, there are psychosocial benefits to wellbeing that include 
increased social capital and cooperation (Moore \& Diener, in preparation), more frequent prosocial behavior and an increase in social relationships and networks (DeNeve, Diener, Tay, \& Xuereb, 2013), more successful relationships such as marriage or friendships (Lyubomirsky, King \& Diener, 2005), increased fertility and fecundity (Diener, Kanazawa, Suh, \& Oishi, 2014), and high levels of altruism and trust (Keltner, Kogan, Piff, \& Saturn, 2014). Such findings are one reason many experts argue for the inclusion of wellbeing in policy development (Diener, Oishi, \& Lucas, 2015).

In light of the increased focus on individual wellbeing, leaders of several countries have endorsed national wellbeing programs. For example, in the United Kingdom, Prime Minister David Cameron supported the establishment of the Measuring National Well-Being Programme. The program aims to measure the UK's national wellbeing beyond that of its economic standing and looks at social, personal and environmental wellbeing as well (Office for National Statistics, 2015). The former president of France, Nicolas Sarkozy, similarly appointed a commission of economists that reached a similar conclusion: that a country's wellbeing reaches far beyond that of its economic prosperity (Stiglitz, Sen, \& Fitoussi, 2009). There have also been multinational efforts in recent years that have been directed at the measurement of wellbeing. The Organization for Economic Cooperation and Development (OECD) produced a set of comprehensive guidelines that outline the instructions for validity, methodology, psychometrics and analyses of wellbeing measures (OECD, 2013).

Smaller-scale wellbeing improvement efforts have also been taking place around the world. For example, the state of Vermont, in the United States, has taken a state-wide wellbeing approach to help citizens thrive (Murphey, 2006). Similarly, the city of Bahia, in Brazil, has also focused on the wellbeing of its citizens as a viable policy goal (World Bank, 2015). Finally, the town of Dragør, Denmark, is conducting a comprehensive study to assess how wellbeing measures can contribute to the creation of public policy (Happiness Research Institute, 2013).

Perhaps the most widely known example of wellbeing policy comes from the nation of Bhutan. In the early 1970s, the fourth King of Bhutan, Jigme Singye Wangchuck, announced that Gross National Happiness (GNH) should be the chief public policy direction for Bhutan (Burns, 2011; Dorji, 2013). The Gross National Happiness Commission for Bhutan published a report in 2006 which presented its rationale for making happiness an integral part of its public policy. The Commission stated that it saw GNH as the primary indicator of the country's overall national development and included commitments to the people of Bhutan such as reducing poverty, achieving gender equality, generating employment, better governance, and capacity building (GNH Commission, 2006). Bhutan defines GNH as having sustainable and equitable socioeconomic development, environmental conservation, and the promotion of culture and good governance. Bhutan's nine indicators of GNH are: health, education, living standards, time use, environmental quality, culture, community vitality, governance, and psychological wellbeing (Burns, 2011) (see Figure 1 below). Bhutan's focus on GNH has been widely publicized and has captured worldwide media attention because of its novel approach to policy (Revkin, 2005).

Despite its popular appeal, and the fact that it is decades old, little is known about the effectiveness of Bhutan's GNH program. Some critics have argued that GNH is nothing more than a publicity stunt (Santos, 2015). On the other hand, supporters have argued that there are legitimate benefits to this policy and have stated that Bhutan "...offers us a...practical, scientific approach for creating a political environment conducive to the pursuit of happiness" (Burns, 2011, p. 85). There has been some research attention directed to Bhutan's levels of wellbeing. One study found that Bhutan ranks eighth on wellbeing on a list of 178 countries (White, 2007). 
Another study (Diener \& Tay, 2015) found that Bhutan's overall wellbeing ranks $26^{\text {th }}$ out of 164 nations. While it is significantly higher than that of other nations in the region, it ranks below some of the developing and Western nations. In the end, there are scant data and a preponderance of speculation regarding the quality of life in Bhutan.

Figure 1: Nine indicators of Gross National Happiness in Bhutan

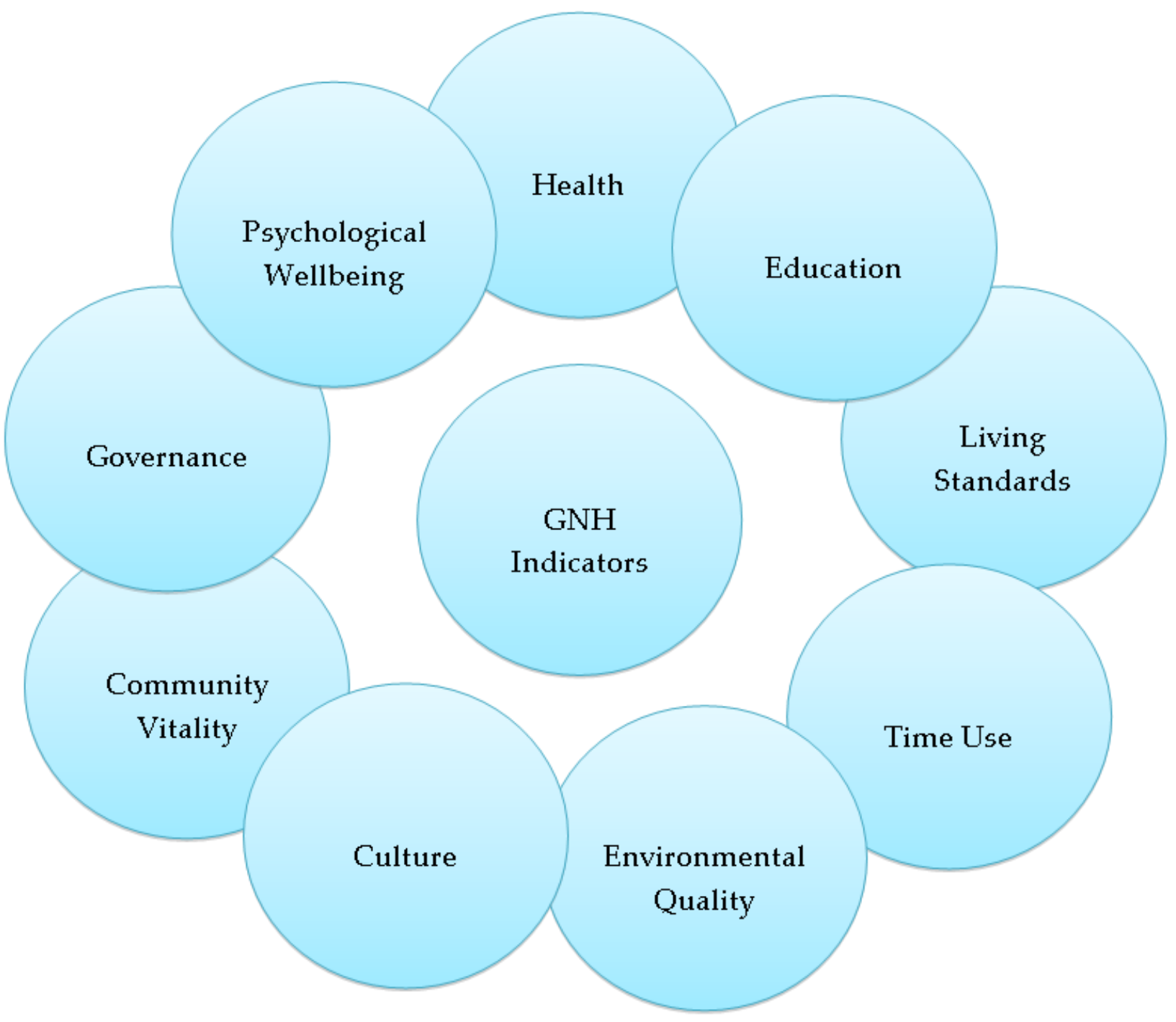

In the current study, we seek to explore the wellbeing of the citizens of Bhutan. To do so, we utilize new data gathered through the Gallup World Poll (2007). This new survey information provides an initial opportunity to evaluate broad metrics of wellbeing in the Kingdom of Bhutan.

\section{Methods}

\subsection{Sampling}

The data for this study were collected by the Gallup Organization as part of the Gallup World Poll (GWP). The GWP includes annual waves of cross-sectional data from 164 nations. The data are demographically representative of age, sex, urban and rural populations, education, number of children, income and other factors. The GWP includes more than 200 items that assess psychological, social, environmental, income, and material wellbeing as well as health, work, 
and security satisfaction. The items include open-ended, Likert-type and dichotomous response formats.

Participants for this study were recruited in one of two ways - if at least $80 \%$ of the population in a given country had telephone coverage respondents were contacted via random digit dialing or using a nationally representative list of phone numbers. The respondents were interviewed over the phone. In technologically developing countries, where phone access is not as widespread, face-to-face interviews were conducted using an area frame design where sampling units were selected through stratification by population size or geography. Then, using random route procedures, specific households were selected and separate individuals were randomly selected within a household using the Kish grid technique (Kish, 1949). All interviews were conducted in the native language of the interviewee.

The specific number of participants included in our current analyses vary by nation, depending on how many waves of data were collected in each country. In each case there are at least one thousand demographically balanced respondents per nation. In many cases, there are tens of thousands of respondents. For example, in this study China is the nation with the largest sample size, with 38,580 individuals participating. Bhutan's sampling $(\mathrm{N}=1,000)$ was conducted during the summer of 2013 (May-July), and was the result of door-to-door contact and face-toface interviewing for the survey.

\subsection{Analytic strategy}

In the current study we compared and contrasted Bhutan with other nations on a wide range of wellbeing variables. We selected 11 candidate nations based on their usefulness as targets of comparison. These 11 nations fell into the following classifications: 3 nations located in the same geographic region as Bhutan - India, Nepal, and China; 3 nations with similar average household incomes as Bhutan- Armenia, Guatemala, and Vietnam; 3 Western nations for potential cultural contrast - United States of America as it is the richest nation of the world and therefore a common target of comparison, Netherlands and Costa Rica, which are comparable in size to Bhutan, and both rank as happy nations but represent differing levels of GDP and have distinct cultures; finally, we included 2 "anchor nations" which represent the top and the bottom-ranking countries on the GWP in terms of wellbeing - Denmark and Burundi.

\subsection{Wellbeing variables}

We selected four domains of interest - psychological, social, environmental, and income and material wellbeing - within the 12 countries. The domains were each assessed using three separate variables, with the exception of psychological wellbeing, which was assessed using six variables. Most of the variable response scales were presented as dichotomous yes/no items, with the exception of the Cantril Self-Anchoring Ladder, which uses a Likert-type answer scale ranging from 0 to 10 . Because there were 164 nations represented in the current study the individual country rankings could range from 1 to 164 (with the exception of certain variables where there was a nation with missing data, in which case the total would be less than 164). Household income was assessed on a continuous scale (reported household income from the previous year).

Psychological wellbeing was measured using a combination of global evaluation and affect items. First, we used the Cantril Self-Anchoring Striving Scale (Cantril, 1965) or "Cantril Ladder." The Cantril Ladder is a self-report global life evaluation measure that asks people to rate their life on a scale (or 'ladder') that ranges from 0 (worst possible life) to 10 (best possible life). This measure allowed us to gauge the individual's subjective evaluations of wellbeing. We also 
employed a range of positive and negative affect items measuring the experience of enjoyment, smiling, worry, sadness, and anger during the day before the data were collected. The items were scored on a Yes/No dichotomous scale. In order to calculate percentages, participants' responses were subtracted from 2 and multiplied by 100.

Social wellbeing was measured using three separate variables asking participants to rate, respectively, whether or not people in their society have respect for children, whether the respondent has a sense of freedom, and whether the respondent has people he or she can count on in case of emergency. These items were also scored on Yes/No dichotomous scales.

Environmental wellbeing was measured by asking participants to report on their perceptions of local air quality, water quality, and environmental protection - i.e. whether or not the aforementioned characteristics are present in their country.

Finally, income and material wellbeing was measured by assessing household income, owning a television and going hungry. Household income was assessed by asking participants to indicate their household income in the past year. Although we recognize that owning a television may not be an indicator of overall wellbeing, it is an indicator of having access to electricity and the material wellbeing associated with access to electricity. The 'going hungry' item asked each respondent to indicate whether they "had gone hungry at any time during the previous year."

\section{Results}

\subsection{Psychological wellbeing}

The results of our comparisons of national levels of psychological wellbeing can be seen in Table 1 below. We included mean Cantril Ladder scores, relative Ladder rankings, the percentage of people in each nation who experienced positive and negative affect, respectively, the previous day, and relative rankings of positive and negative affect. Bhutan ranks 65th in Life Evaluation as measured by the Cantril Ladder. Bhutanese respondents reported higher life evaluations ( $M$ $=5.57, S D=1.28$ ) than did respondents from other countries in the same geographic region. The Bhutanese respondents also reported higher life evaluations than did their counterparts in countries with similar average annual incomes. In general, Bhutan has lower mean life evaluations than the Western nations in our analyses. Finally, the Bhutanese respondents reported much higher mean life evaluations than people living in the lowest anchor nation, Burundi $(M=3.69, S D=1.59)$, but much lower mean life evaluations than people living in the highest anchor nation, Denmark $(M=7.77, S D=1.53)$. With regards to affect, Bhutan ranks $28^{\text {th }}$ in overall Positive Affect (78 percent) and $62^{\text {nd }}$ in Negative Affect (22 percent).

Table 1: Psychological wellbeing

\begin{tabular}{lccccrr}
\hline & $\begin{array}{c}\text { Ladder } \boldsymbol{M} \\
(S D)\end{array}$ & $\begin{array}{c}\text { Ladder } \\
\text { ranking }\end{array}$ & PA & PA ranking & NA & NA ranking \\
\hline Bhutan & $5.57(1.28)$ & 65 & $78 \%$ & 28 & $22 \%$ & 62 \\
China & $4.87(1.91)$ & 108 & $82 \%$ & 17 & $15 \%$ & 7 \\
India & $4.79(1.89)$ & 113 & $66 \%$ & 63 & $28 \%$ & 110 \\
Nepal & $4.43(1.70)$ & 128 & $75 \%$ & 58 & $21 \%$ & 48 \\
\hline Armenia & $4.40(2.03)$ & 131 & $52 \%$ & 98 & $43 \%$ & 160 \\
Guatemala & $6.12(2.36)$ & 43 & $84 \%$ & 10 & $27 \%$ & 106 \\
Vietnam & $5.41(1.44)$ & 77 & $62 \%$ & 79 & $21 \%$ & 45 \\
\hline Costa Rica & $7.24(2.06)$ & 12 & $83 \%$ & 10 & $24 \%$ & 77 \\
Netherlands & $7.50(1.29)$ & 4 & $85 \%$ & 7 & $21 \%$ & 56 \\
USA & $7.19(1.98)$ & 14 & $83 \%$ & 15 & $25 \%$ & 84 \\
\hline Burundi & $3.69(1.59)$ & 162 & $60 \%$ & 83 & $20 \%$ & 44 \\
Denmark & $7.77(1.53)$ & 1 & $84 \%$ & 11 & $19 \%$ & 30 \\
\hline
\end{tabular}


In an effort to illustrate national standings relative to Denmark we have placed ladder scores on a single continuum, as can be seen in Figure 2 below. Although the ladder scale ranges from 0 to 100 , the respondents from the nation with the least positive life evaluations (Burundi) still reported an average score of 47 . This visual aid is helpful in understanding the relative distances between mean national scores. As can be seen, Bhutan ranks above many of its geographic and income "neighbors". That said, Bhutan still falls sort of the overall life evaluations reported by respondents from Western and more economically developed nations.

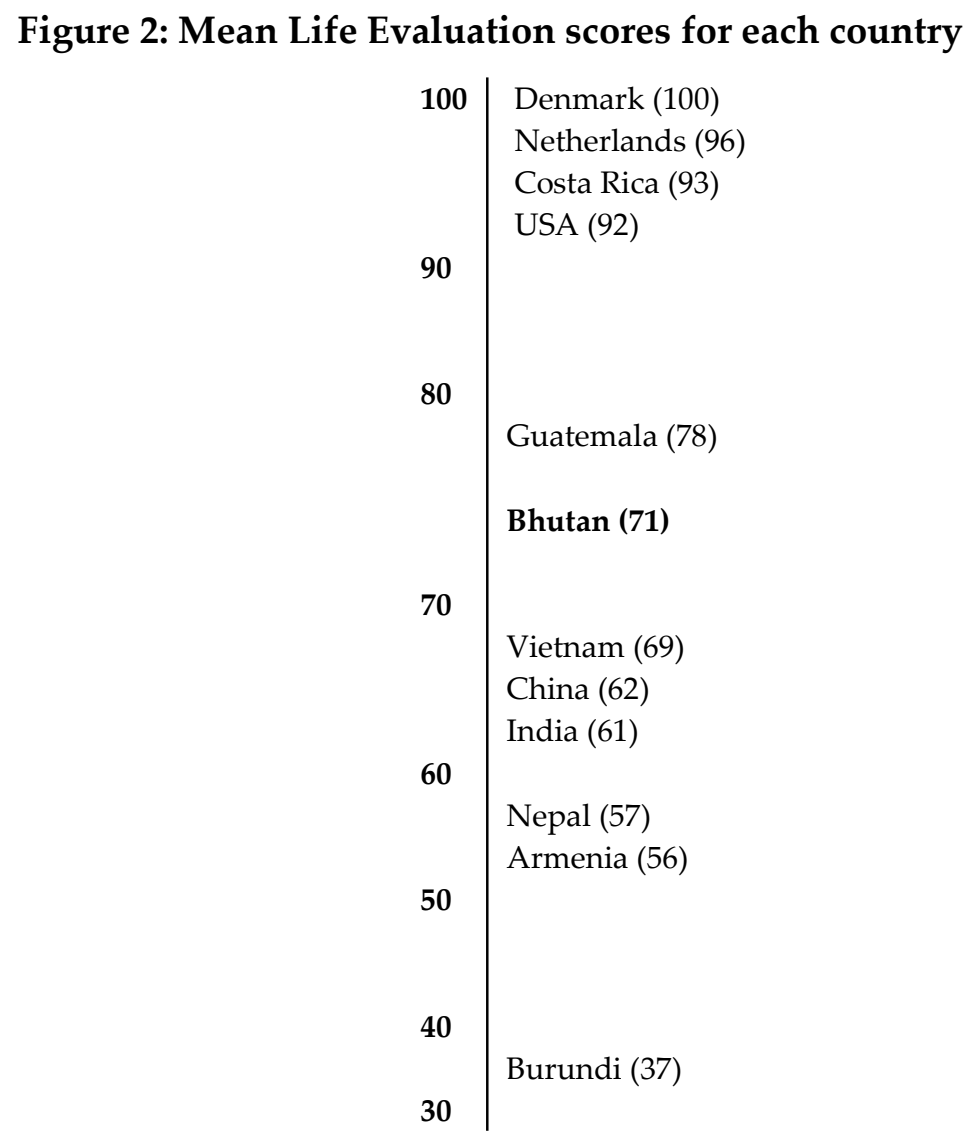

To illustrate the distribution of Cantril's Self-Anchoring Ladder for Bhutan, in Figure 3 below we have displayed the percentage of respondents who have selected a given point on this scale between 0 and 10. Eighty-three percent of respondents gave responses that were in the middle to slightly positive and there were very few respondents who were either extremely satisfied or extremely dissatisfied.

With regard to positive and negative affect, one can clearly see that Bhutan scores fairly high on positive affect ( $28^{\text {th }}$ of 162 nations). A closer examination of the data reveals that $68 \%$ of the Bhutanese respondents reported that they experienced "a lot" of both enjoyment and laughter on the day preceding the survey. Only $10 \%$ of the Bhutanese respondents indicated that they did neither. 
Figure 3: Distribution of scores for positive Life Evaluations (Bhutan)

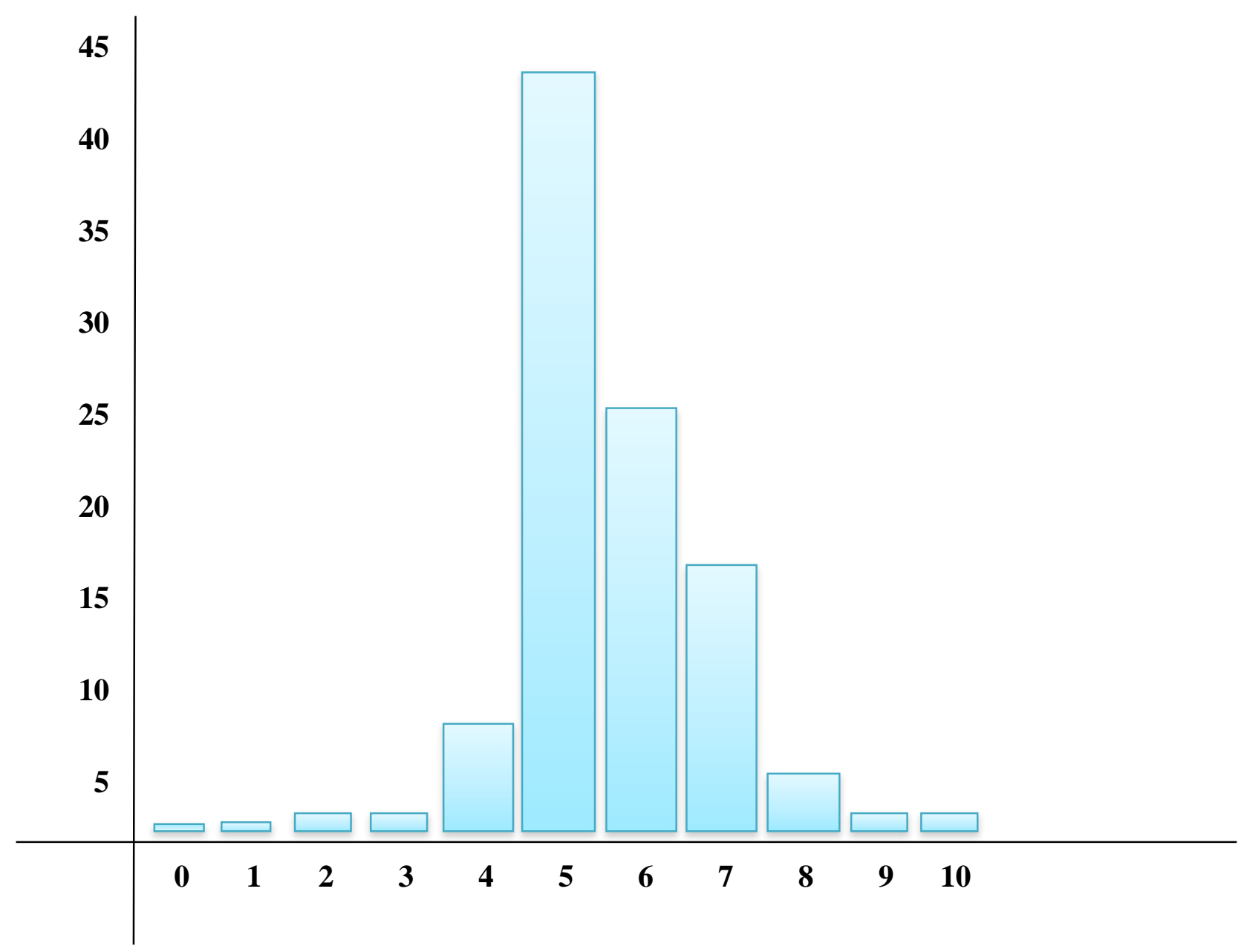

\subsection{Social wellbeing}

The results of our comparisons of national level social wellbeing are presented in Table 2 below. As can be seen, Bhutan has the highest average reported rates for respect for children (95\%), as compared with all 11 other countries in this study, including the United States (70\%). With regard to having the freedom to choose what they want to do with their lives, the Bhutanese people score the same as China ( $81 \%$ for both nations), but lower than Western nations. Regarding the ability to count on others in the time of need, Bhutan scores the same as Vietnam (82\%), but again, lower than Western nations. 
Table 2: Social wellbeing

\begin{tabular}{lccc}
\hline & Respect for children & Freedom & Count on others \\
\hline Bhutan & $95 \%$ & $81 \%$ & $82 \%$ \\
China & $92 \%$ & $81 \%$ & $78 \%$ \\
India & $73 \%$ & $71 \%$ & $58 \%$ \\
Nepal & $54 \%$ & $60 \%$ & $78 \%$ \\
\hline Armenia & $79 \%$ & $49 \%$ & $70 \%$ \\
Guatemala & $35 \%$ & $72 \%$ & $83 \%$ \\
Vietnam & $89 \%$ & $87 \%$ & $82 \%$ \\
\hline Costa Rica & $63 \%$ & $90 \%$ & $91 \%$ \\
Netherlands & $84 \%$ & $90 \%$ & $94 \%$ \\
USA & $70 \%$ & $85 \%$ & $93 \%$ \\
\hline Burundi & $54 \%$ & $39 \%$ & $35 \%$ \\
Denmark & $83 \%$ & $94 \%$ & $96 \%$ \\
\hline
\end{tabular}

Note: Numbers indicate the percentage of respondents who positively endorsed each variable

\subsection{Environmental wellbeing}

The results of our comparisons of national level environmental wellbeing can be seen in Table 3 below. Bhutan scores higher than 10 of the 11 comparison countries on air quality at $92 \%$ and is equal to that reported by the top anchor country, Denmark. In terms of water quality, Bhutan ranked right in the middle of the remaining countries and lower than Western nations (81\%). With regard to overall environmental protection Bhutan scored the highest of all countries in our study $(95 \%)$.

Table 3: Environmental wellbeing

\begin{tabular}{lccc}
\hline & Air Quality & Water Quality & Environmental Protection \\
\hline Bhutan & $92 \%$ & $81 \%$ & $95 \%$ \\
China & $76 \%$ & $75 \%$ & $76 \%$ \\
India & $86 \%$ & $66 \%$ & $56 \%$ \\
Nepal & $89 \%$ & $82 \%$ & $55 \%$ \\
\hline Armenia & $61 \%$ & $66 \%$ & $31 \%$ \\
Guatemala & $81 \%$ & $69 \%$ & $45 \%$ \\
Vietnam & $72 \%$ & $75 \%$ & $65 \%$ \\
\hline Costa Rica & $85 \%$ & $89 \%$ & $65 \%$ \\
Netherlands & $81 \%$ & $94 \%$ & $68 \%$ \\
USA & $86 \%$ & $87 \%$ & $57 \%$ \\
\hline Burundi & $83 \%$ & $51 \%$ & $54 \%$ \\
Denmark & $92 \%$ & $96 \%$ & $65 \%$ \\
\hline
\end{tabular}

Note: Numbers indicate the percentage of respondents who positively endorsed each variable

\subsection{Income and material wellbeing}

The results of our comparisons of national income and material wellbeing can be seen in Table 4 below. Bhutan ranks 92 ${ }^{\text {nd }}$ in terms of overall income (Diener \& Tay, 2015) and eighth of the 12 comparison nations. In terms of having a television set, $76 \%$ of individuals in Bhutan have one (whereas $8 \%$ of Bhutanese respondents report having Internet). With regards to going hungry, only a small minority of individuals report suffering from hunger $(6 \%)$.

Although the respondents in Bhutan report going hungry at higher rates than are reported by their counterparts in the industrialized nations, in our study they report lower rates of hunger than do their geographic and income counterparts. 
Table 4: Income and material wellbeing

\begin{tabular}{lccc}
\hline & Household Income (\$) & Having a television & Gone hungry \\
\hline Bhutan & $5,956.07$ & $76 \%$ & $6 \%$ \\
China & $9,193.52$ & $97 \%$ & $3 \%$ \\
India & $4,209.95$ & $66 \%$ & $15 \%$ \\
Nepal & $4,124.87$ & $58 \%$ & $10 \%$ \\
\hline Armenia & $5,090.42$ & $98 \%$ & $9 \%$ \\
Guatemala & $6,609.12$ & $94 \%$ & $16 \%$ \\
Vietnam & $6,531.74$ & $96 \%$ & $7 \%$ \\
\hline Costa Rica & $12,815.22$ & $98 \%$ & $9 \%$ \\
Netherlands & $46,243.46$ & $98 \%$ & $1 \%$ \\
USA & $56,386.75$ & $98 \%$ & $3 \%$ \\
\hline Burundi & $1,073.48$ & $2 \%$ & $46 \%$ \\
Denmark & $51,363.14$ & $98 \%$ & $2 \%$ \\
\hline
\end{tabular}

Note: With the exception of the income figures, numbers indicate the percentage of respondents who positively endorsed each variable

In an effort to illustrate Bhutan's standing relative to the other nations on these other indices of wellbeing - social, environmental and income/material - we have depicted the relative rankings on a single continuum, seen in Figures 4 and 5 below. We created an index score by averaging the three social and three environmental variables and placed them on a continuum between the highest $(100 \%)$ and the lowest $(0 \%)$. As can be seen, for both the social and environmental indices, Bhutan ranks above both its geographic and income "neighbors". These figures are informative in that they present a concrete visual representation of the relative position of nations on these dimensions.

Figure 4: Social wellbeing

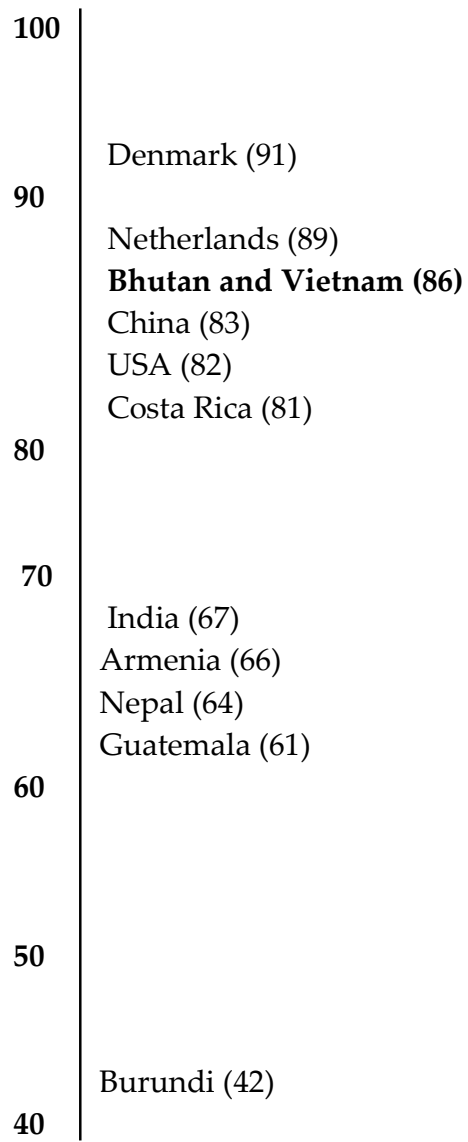




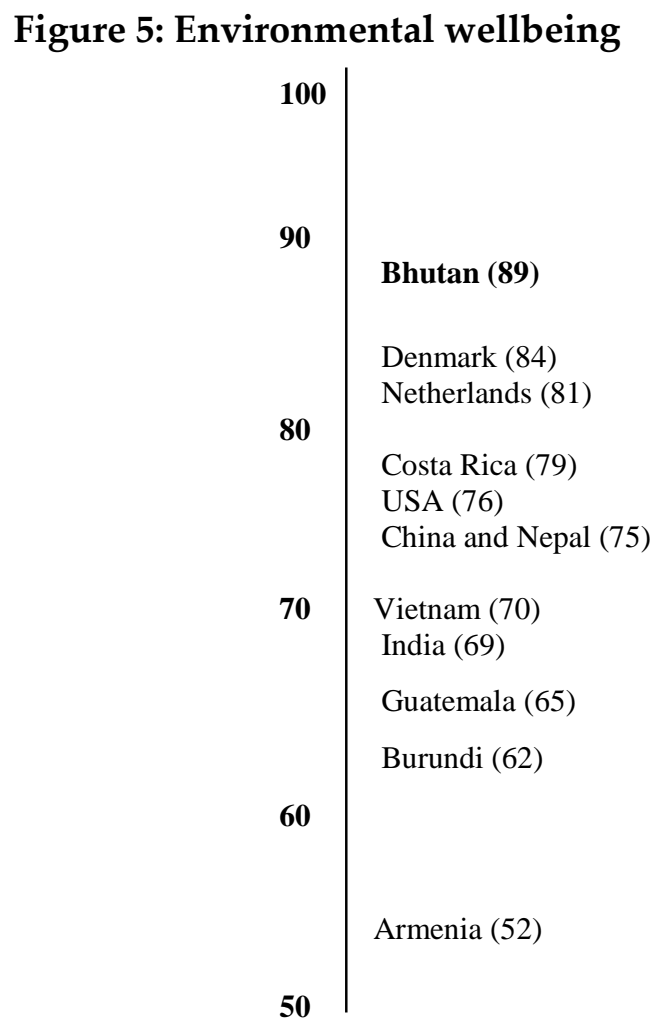

\section{Conclusion}

It is easy to romanticize the citizens of Bhutan as living in Shangri La, a kingdom of peace, harmony, and happiness. It is just as it is easy to cynically dismiss the Gross National Happiness approach as being nothing more than a publicity stunt. We are able to investigate the wellbeing of Bhutanese people on a wide range of dimensions and, perhaps more importantly, are able to compare these scores with those from people from a wide range of nations.

Starting with measures of psychological wellbeing, we see that the Bhutanese score in the middle of nations. They are not distinguished by exceptionally high levels of psychological wellbeing, as the romantic notion would hold, but nor are they obviously deficient in psychological wellbeing, as the cynical view would hold. It appears that people in Bhutan enjoy adequate psychological wellbeing and that they generally appear to live happier lives than their counterparts in geographically and economically similar nations. In an absolute and also in an overall relative sense, Bhutan is doing moderately well.

Interestingly, an investigation of other types of wellbeing, most notably social and environmental, helps paint a slightly more complex portrait of Bhutanese happiness. On both of these dimensions the Bhutanese respondents in the current study reported very high scores. Specifically, Bhutan scored the highest of any nation on environmental wellbeing and higher than all other candidate nations except Denmark and the Netherlands on social wellbeing. This suggests that Bhutan's superior standing relative to its income and geographic counterparts might be related to social and environmental variables. While Bhutan's high standing on these variables does not appear to translate directly to exceptionally high psychological wellbeing, it could be that social and environmental factors buffer Bhutanese people from problems that otherwise lower the quality of life for their regional counterparts and income peers in terms of economic development. In particular, it should be noted that Bhutan is not a highly economically developed country. Only about three-quarters of the Bhutanese respondents reported having electricity and $6 \%$ went hungry during the previous year. Given these somewhat impoverished 
material circumstances, the social, psychological, and environmental wellbeing of the nation is higher than one might expect.

There are, of course, several limitations in the current study. One of the limitations of this study is missing information. For instance, no data were available for rates of access to electricity in Bhutan. Another limitation is that we used a cross-sectional sample that represents a single point in time and thus does not give a sense of temporal development in the data. Looking at waves of data in the future will be essential to building confidence in these conclusions and in terms of understanding the direction in which Bhutan is moving. Additionally, it would be beneficial to assess the same individuals in a longitudinal study to see how the GNH policy has affected their lives over time. Future study could also improve on the current investigation by employing a multi-method approach. The data we used were all based on self-report surveys, and could be supplemented in the future by other types of measures of wellbeing, including peer report or experience sampling. Finally, we argue that it would be entirely appropriate to connect new measures of wellbeing collected in the future with measures of Bhutan's nine GNH indicators.

In the end, Bhutan may not be the Shangri La the popular media sometimes hold it out to be. We found legitimate problems, such as hunger and far from perfect happiness, in our current investigation. That said, it is also clear that Bhutan might offer an instructive lesson on ways that social and environmental policy can buffer citizens from certain material deprivations. Bhutan is higher on many indices of wellbeing than many of its geographic and income neighbors.

\section{Authors}

Robert Biswas-Diener

Portland State University

robert@positiveacorn.com

Ed Diener

University of Virginia and The Gallup Organization

Nadezhda Lyubchik

Positive Acorn

\section{Publishing Timeline}

Received 6 April 2015

Accepted 18 April 2015

Published 21 June 2015

\section{References}

Burns, G.W. (2011). Gross National Happiness: A gift from Bhutan to the world. In. R. Biswas-Diener (Ed.), Positive psychology as social change (pp. 73-87). New York, NY: Springer. http://dx.doi.org/10.1007/978-90-481-9938-9 5

Cantril, H. (1965). The pattern of human concern. New Brunswick, NJ: Rutgers University Press.

Clark, A. E., Diener, E., Georgellis, Y., \& Lucas, R. E. (2008). Lags and leads in life satisfaction: a test of the baseline hypothesis. The Economic Journal, 118, F222-F243. http://dx.doi.org/10.1111/j.1468$\underline{0297.2008 .02150 . x}$

DeNeve, J-E., Diener, E., Tay, L., \& Xuereb, C. (2013). The objective benefits of subjective well-being. In J. F. Helliwell, R. Layard, \& J. Sachs (Eds.), World happiness report 2013. Volume 2. (pp. 54-79). New York: UN Sustainable Network Development Solutions Network. 
Diener, E., Inglehart, R., \& Tay, L. (2013). Theory and validity of life satisfaction scales. Social Indicators Research, 112, 497-527. http://dx.doi.org/10.1007/s11205-012-0076-y

Diener, E., Kanazawa, S., Suh, E. M., \& Oishi, S. (2014). Why people are in a generally good mood. Personality and Social Psychology Review, 1-22. http://dx.doi.org/10.1177/1088868314544467

Diener, E., Lucas, R. E., Schimmack, U., \& Helliwell, J. (2009). Well-being for public policy. New York, NY: Oxford University Press. http://dx.doi.org/10.1093/acprof:oso/9780195334074.001.0001

Diener, E., Oishi, S., \& Lucas, R. E. (2015). National accounts of subjective well-being. American Psychologist, 70(3), 234-242.http://dx.doi.org/10.1037/a0038899

Diener, E., \& Tay, L. (2013). The benefits of happiness for successful and healthy living. Report of well-being and happiness. Contributions toward the Royal Government of Bhutan's NDP Report by IEWG members of the well-being and happiness working group.

Diener, E., \& Tay, L. (2015). Subjective well-being and human welfare around the world as reflected in the Gallup World Poll. International Journal of Psychology, 50(2), 135-149.

Diener, E., Wirtz, D., Tov, W., Kim-Prieto, C., Choi, D.W., Oishi, S., \& Biswas-Diener, R. (2010). New well-being measures: Short scales to asses flourishing and positive and negative feelings. Social Indicators Research, 97, 143-156. http://dx.doi.org/10.1007/s11205-009-9493-y

Dorji, C. T. (2013). Milestones in the development of gross national happiness concept.

Gallup World Poll. (2007). The state of global well-being. New York, NY: Gallup Press.

GNH Commission (2006). Keeping promises: A report on the status of implementation of the Brussels programme of action in Bhutan for the decade (2001-2010). http://www.un.org/en/conf/ldc/pdf/bhutan.pdf

Happiness Research Institute. (2013). Dragør municipality happiness survey 2013. http://www.happinessresearchinstitute.com/projects/4579836746

Hooker, E. \& Pressman, S. (2015). The healthy life. http://nobaproject.com/modules/the-healthylife\#content

Keltner, D., Kogan, A., Piff, P. K., \& Saturn, S. R. (2014). The sociocultural appraisals, values, and emotions (SAVE) framework of prosociality: Core processes from gene to meme. Annual Review of Psychology, 65, 425-460. http://dx.doi.org/10.1146/annurev-psych-010213-115054

Kish, L. (1949). A procedure for objective respondent selection within the household. Journal of the American Statistical Association $44,380-387$.

Lyubomirsky, S., King, L., \& Diener, E. (2005). The benefits of frequent positive affect: does happiness lead to success? Psychological Bulletin, 131, 803-855. http://dx.doi.org/10.1037/0033-2909.131.6.803

Moore, S., \& Diener, E. (in preparation). Happiness enhances social relationships. University of Utah, in preparation.

Murphey, D. (2006). Vermont well-being: A social indicators sourcebook. http://humanservices.vermont.gov/publications/vermont-well-being-2006

OECD (2013). OECD guidelines on measuring subjective well-being. OECD Publishing. http://dx.doi.org/10.1787/9789264191655-en

Office for National Statistics. (2015). Measuring national well-being. http://www.ons.gov.uk/ons/guidemethod/user-guidance/well-being/index.html

Pavot, W., \& Diener, E. (2008). The Satisfaction With Life Scale and the emerging construct of satisfaction with life. Journal of Positive Psychology, 3, 137-152. http://dx.doi.org/10.1080/17439760701756946

Pavot, W., \& Diener, E. (1993). Review of the satisfaction with life scale. Psychological Assessment, 5, 164. http://dx.doi.org/10.1037/1040-3590.5.2.164

Revkin, A.C. (2005). A new measure of well-being from a happy little kingdom. http://www.nytimes.com/2005/10/04/science/04happ.html?pagewanted=all

Sandvik, E., Diener, E., \& Seidlitz, L. (1993). Subjective well-being: The convergence and stability of selfreport and non-self-report measures. Journal of Personality, 61, 317-342. http://dx.doi.org/10.1111/j.1467-6494.1993.tb00283.x

Santos, L.A. (2015). Time for Bhutan and the world to give 'happiness' a second look. https://www.devex.com/news/time-for-bhutan-and-the-world-to-give-happiness-a-second-look$\underline{85321}$ 
Stiglitz, J. E., Sen, A., \& Fitoussi, J-P. (2009). Report by the Commission on the Measurement of Economic Performance and Social Progress. http://www.stiglitz-sen-fitoussi.fr/en/index.htm

White, A. (2007). A global projection of subjective well-being: A challenge to positive psychology? Psychtalk, 56, 17-20.

World Bank. (2015). Brazilian projects among the most inspiring in the world.

http://www.worldbank.org/en/news/feature/2012/08/03/projetos-brasileiros-100-mais-inovadoresmundo 